\title{
AS INTERNAÇÕES SEM CONSENTIMENTO DE USUÁRIOS DE DROGAS NO ESTADO DO TOCANTINS
}

\section{INVOLUNTARY HOSPITALIZATIONS OF DRUG USERS AT THE STATE OF TOCANTINS}

\author{
Deise Justino Matos ${ }^{1}$ \\ Cristiane Roque de Almeida ${ }^{2}$
}

\section{RESUMO:}

O presente artigo versa sobre as internações sem consentimento de usuários de drogas no Estado do Tocantins. Objetivou-se a análise do desenvolvimento das internações sob a perspectiva das obrigações impostas pela da Lei $n^{0} 10.216 / 2001$. O estudo do caso tocantinense ocorreu por meio de análise documental, utilizando-se do método indutivo para produzir pesquisa de natureza aplicada e de finalidade exploratória e descritiva, envolvendo procedimento de pesquisa bibliográfica e jurisprudencial. Os resultados encontrados demonstraram graves violações à Lei $\mathrm{n}^{\circ}$ 10.216/2001 bem como a normas regulamentadoras, evidenciando o caráter asilar das internações ocorridas em instituição conveniada com o Estado desde o ano de 2013 até 2016.

Palavras-chave: Estado do Tocantins. Internação involuntária e compulsória. Lei noำ $10.216 / 2001$.

\section{ABSTRACT:}

This article discusses the occurrence of involuntary hospitalizations of drug users at the State of Tocantins. The purpose of this study was to analyze the development of involuntary hospitalizations from the perspective of the obligations imposed by Law $n^{\circ}$ 10.216/2001. The study of the case of Tocantins occurred through documentary analysis, using the inductive method to produce research of an applied nature and an exploratory and descriptive purpose, involving a procedure of bibliographical and jurisprudential research. The results found demonstrated serious violations of the Law no $10.216 / 2001$ as well as it regulatory norms, evidencing the asylum character of

\footnotetext{
${ }^{1}$ Bacharela em Direito pela Universidade Federal do Tocantins - UFT. E-mail: deisejustino@gmail.com.

${ }^{2}$ Mestra pela Universidade Federal de Goiás, Professora da Universidade Federal do Tocantins-UFT, Coordenadora do Centro Regional de Referência sobre Drogas do Tocantins (CRR/UFT/CENTRO-SUL), Vice-líder do Grupo de Estudos sobre Drogas - GED, ambos da Universidade Federal do Tocantins. E-mail: crisroque@mail.uft.edu.br
} 
hospitalizations occurred in an institution agreed with the State of Tocantins from the year 2013 to 2016.

Key words: State of Tocantins. Involuntary hospitalizations. Law no 10.216/2001.

\section{INTRODUÇÃO}

O presente artigo constitui-se em um recorte de pesquisa sobre as modalidades de internação que dispensam o consentimento do usuário de drogas categorizado como dependente químico, bem como sobre os procedimentos e requisitos legais para tais tipos de internação, nos termos da Lei no 10.216/2001, denominada Lei Antimanicomial.

A referida lei federal é resultante de um movimento histórico denominado Reforma Psiquiátrica Brasileira, o qual se insurgiu contra o modelo manicomial de tratamento da saúde mental, promovendo denúncias quanto à estrutura assistencial vigente e propondo a elaboração de um novo paradigma voltado à humanização do tratamento e resgate da cidadania do paciente portador de transtornos mentais.

Apesar do dissenso acadêmico, o usuário de drogas, lícitas ou ilícitas, na condição de dependente químico, é tido pelo Código Internacional de Doenças (CID10) da Organização Mundial de Saúde (OMS) e pelo Manual de Diagnóstico e Estatística dos Transtornos Mentais (DSM) da Associação Americana de Psiquiatria (AAP) como portador de transtorno mental crônico, e por inexistir rol legal que defina taxativamente a quem se aplica a Lei oㅜ 10.216/2001, esta vem sendo aplicada ao "dependente químico" por meio de interpretação analógica.

Para verificar como essas modalidades de internações ocorreram de 2013 até o início do ano de 2017 no estado do Tocantins, esta pesquisa foi realizada por meio de abordagem indutiva, qualitativa, exploratória e descritiva, envolvendo procedimentos de pesquisa bibliográfica e análise documental pormenorizada dos relatórios de inspeção realizados nos anos de 2013, 2015 e 2016 concedidos pelo Núcleo de Defesa a Saúde da Defensoria Pública do Estado do Tocantins (NUSA-DPE-TO), Conselho Estadual sobre Drogas do Tocantins (CONESD-TO) e Conselho Regional de Medicina do Estado 
do Tocantins (CRM-TO), além do Inquérito Civil no 18/2016 do Ministério Público Estadual por meio da $7^{\text {a }}$ Promotoria de Justiça da Comarca de Porto Nacional.

Neste texto, incialmente parte-se de uma delimitação dos conceitos de droga e dependência química adotados no decorrer no trabalho e dos fundamentos da internação psiquiátrica para os indivíduos considerados dependentes químicos e, na sequência, apresenta-se os resultados da análise do modo pelo qual as internações sem consentimento foram desenvolvidas no Estado do Tocantins.

\section{INTERNAÇÕES PSIQUIÁTRICAS DE USUÁRIOS DE DROGAS: CONCEITUAÇỔES, FUNDAMENTOS JURÍDICOS E PROCEDIMENTOS LEGAIS}

Em perspectiva interdisciplinar ora adotada, entende-se que a compreensão dos conceitos de droga e dependência química são relevantes à determinação de quem é realmente portador dessa doença e de qual substância a induz, podendo afetar a capacidade civil de forma a haver a possibilidade de submissão ao tratamento forçado, para posteriormente discorrer acerca do que consiste o referido tratamento.

De acordo com Olmo (1990), o conceito de droga possui demasiada amplitude e imprecisão, incluindo em seu rol uma quantidade de substância de efeitos e finalidades muito distintas, cujo grau de perturbação não condiz com sua proibição ou liberação. Ressalta a autora que a OMS, compreende droga "toda substância que, introduzida em um organismo vivo, pode modificar uma ou mais funções deste" (OLMO, 1990, p.16).

Destaca Fiore (2006, p. 64) que, para a farmacologia contemporânea, o conceito de droga abarca "todas substâncias que provoquem alguma mudança fisiológica num corpo sem ser fundamental para sua sobrevivência", sendo pelo autor considerado tão impreciso quanto o termo da OMS, cabendo na mesma definição substâncias muito diversas e com tratamentos muito diferentes. Por exemplo, é notável no discurso tanto popular quanto médico o tratamento diferenciado dispensado ao álcool, tabaco, cafeína e remédios, como se pertencessem a outra categoria de substâncias que não a de drogas, enquanto todos incluem listas de substâncias que induzem à dependência química. 
Os termos "narcóticos" e "entorpecentes" para designar as drogas foram deixados de lado pelos profissionais de saúde, mas permanecem na linguagem policial e jurídica, no entanto, o termo "susbtância psicoativa" como sinônimo de droga é amplamente utilizado até mesmo no discurso médico, enquanto não é a psicoatividade característica definidora do conceito de droga para a OMS (FIORE, 2006).

No Brasil, a Lei de Drogas, Lei ㄲo 11.343/2006, a qual instituiu o Sistema Nacional de Políticas Públicas sobre Drogas - SISNAD, logo em seu art. 1e evidencia a busca pelo tratamento diferenciado entre o usuário, a pessoa em uso indevido, o dependente e o traficante de drogas, demonstrando a preocupação da legislação em realizar esta diferenciação e conferir trato específico às necessidades de cada categoria. No que concerne à diferenciação entre os padrões de consumo, sua relevância se exsurge para a determinação de tratamento médico, para o tratamento civil no plano das capacidades, o tratamento pelo direito securitário, bem como para tratamento penal no plano da imputabilidade.

Para o Ministério da Justiça (BRASIL, 2015), uso de drogas constitui a autoadministração da substância, independentemente da quantidade, enquanto 0 abuso de drogas pode ser compreendido como o uso de modo que gere risco de prejuízo físico, mental ou social para o usuário. Era tratado pelo Manual Diagnóstico e Estatístico de Transtornos Mentais em sua 4⿳亠丷a edição, DSM-IV (AAP), como "abuso" e pelo CID-10 (OMS) como "uso nocivo", trazendo ambos critérios diagnósticos do abuso o fracasso em tarefas importantes, uso recorrente e continuado que represente risco ao usuário, a não satisfação de critérios para qualquer outro transtorno relacionado à mesma substância no mesmo período exceto intoxicação aguda, entre outros. Contudo, já para o pelo Manual Diagnóstico e Estatístico de Transtornos Mentais em sua 5a edição, DSM-V, o abuso e a dependência passaram a não ser diferenciados, persistindo a diferenciação somente para o Código Internacional de Doenças, CID-10.

A dependência química, para o DSM-V e o CID-10, apresentam sintomas como compulsão pelo consumo (fissura), comprometimento da capacidade de controlar o uso, experimentar o estado fisiológico de abstinência, abandono de atividades sociais em detrimento do uso, tolerância aos efeitos da droga, uso persistente em situação de 
risco. O tratamento, conforme o Nota Técnica Núcleo de Avaliação de Tecnologias em Saúde do Hospital das Clínicas da Universidade Federal de Minas Gerais (2014), não possui protocolo unificado, devendo o plano ser individualizado ao sujeito e às peculiaridades do caso. Conforme a referida nota, as internações sem consentimento são necessárias desde que breves e em situações de risco para desintoxicação, ao passo que as internações sem consentimento prolongadas são desencorajadas pela OMS.

Em tempos passados, a dependência química já foi considerada um problema puramente social, educacional ou espiritual, que levava a um tratamento em dimensão única, muitas vezes ineficaz (OMS, 2008). No entanto, a OMS reconhece a dependência química como um transtorno de saúde multifatorial, que frequentemente segue o caminho da doença crônica. O custo do tratamento bem realizado, tanto de prevenção quanto controle, é menor que os custos sociais (saúde, criminalidade, produtividade social perdida) da dependência química sem tratamento ou mal tratada (OMS, 2008), razões que justificam o dispêndio de atenção e custos do orçamento público ao tratamento do problema de abuso dessas substâncias. Acerca disso, no que tange ao reconhecimento da amplitude sociológica envolta na problemática da dependência química, Edward McRae (2003) aponta que enfrentamento às drogas que perde de vista os detalhes sociais do uso conduz ao mero e ineficaz proibicionismo, sem a efetividade social e tratamento que se espera.

O fato é que, no presente momento de evolução histórico-jurídica de compreensão do problema, o dependente químico é visto como portador de transtorno mental, o que consiste na fundamentação autorizadora da internação do paciente sem seu consentimento, permitindo que por ele seja decidido o seu tratamento, com fundamento nos requisitos da Lei oㅜ 10.216/2001.

É preciso constante atenção às consequências desse tipo de diagnóstico, para que não resulte em categorização feita sem a consideração dos critérios técnicos necessários e pautada por critérios totalmente subjetivos e preconceituosos. Trata-se de um tipo de avaliação que requer avaliação por equipe de saúde devidamente capacitada, considerando-se inclusive que a internação não consiste em único modelo 
de tratamento do uso e do abuso de drogas, mesmo que o indivíduo seja diagnosticado como dependente, havendo alternativas menos invasivas e métodos ambulatoriais de recuperação e tratamento que podem ter sua prescrição avaliada, de acordo com cada caso em particular.

A dependência química, por ter origem multifatorial, de dimensões psicológicas, biológicas e até sociais, bem como natureza crônica, configura-se em doença complexa e de difícil acepção do termo cura, mas de ótimas possibilidades de controle (SILVA, 2009). A finalidade do tratamento deve consistir em controlar o abuso de drogas, tornar o paciente produtivo por meio de sua reinserção e permanência em seu meio familiar, profissional e comunitário. Entre os métodos estão o tratamento medicamentoso, psicoterapia, grupos de ajuda mútua, técnicas de redução de danos sociais e à saúde, entre outros. Importante que o processo terapêutico sempre considere o indivíduo como ser integral e multideterminado.

A institucionalização do portador de transtornos mentais foi estudada por Goffman (1974), tendo este conferido a denominação de "instituições totais" aos locais onde grande números de indivíduos de mesma categoria são separados da sociedade por longo tempo, levando a vida integralmente dentro dele. Em contrapartida às instituições totais surgiu o princípio da incompletude institucional, originalmente desenvolvida para o tratamento da questão de menores de idade infratores, mas igualmente aplicável ao caso do portador de doença mental independente da idade, por ambos serem indivíduos vulneráveis e seus tratamentos buscarem a reinserção e readaptação social. O referido princípio propôe que as instituições que promovem tratamentos sejam mais incompletas quanto possível no sentido de obrigatoriamente levar o paciente ao contato com seu exterior e pessoas fora do ambiente institucional, através de atividades comunitárias e intersetoriais (HAMOY, 2008).

Desta forma, restou demonstrado que o conceito de droga é primordial para a determinação de quais substâncias induzem a dependência química, vindo a estabelecer ainda qual tratamento o indivíduo receberá. Entretanto, no que se refere às possibilidades de tratamento, a depender da classificação ou não da substância da 
qual o indivíduo é dependente, isto determinará qual estigma ${ }^{3}$ recairá sobre si, como sua capacidade civil será tratada e quais as repercussões penais do seu envolvimento com a substância, bem como a possibilidade jurídica ou não do ser tratado sem o seu consentimento.

O estigma que é atribuído ao usuário de droga em sentido amplo (uso não nocivo, nocivo ou dependente) revela grandes semelhanças com os fundamentos das políticas proibicionistas como as pré-concepções de que não existe padrão seguro de uso de droga por ser prática intrinsecamente prejudicial à saúde e aos laços sociais, e a necessidade do Estado de reprimir os que produzem, vendem ou consomem drogas (FIORE, 2012) ${ }^{4}$.

A partir disso, e por meio da demonstração da inexistência de protocolo determinado para o tratamento da dependência química, bem como a variedade de tratamentos e abordagens, faz-se necessário esclarecer sua excepcionalidade enquanto doença em questão em relação a outras, desconstruir estigmas que dificultam a abordagem, evidenciar a necessidade de individualização do tratamento ao paciente, assim como reafirmar a extraordinariedade da medida de internação frente às possibilidades de tratamentos voluntários e extra hospitalares.

De um ponto de vista médico-jurídico, de acordo com o Código Internacional de Doenças da OMS (2008), dependente químico é o portador de transtorno mental crônico catalogado no CID-10 entre os códigos F-10 e F-19. Cabe destacar, no entanto, que tal catalogação é dissenso dentro da comunidade médica psiquiátrica (FIORE, 2006). Desta forma, por inexistir rol legal do que seja transtorno mental, essa generalidade normativa será suprimida pela interpretação analógica/extensiva da Lei no

\footnotetext{
${ }^{3}$ Conforme Goffman (1974, 2008).

${ }^{4}$ Pesquisa realizada pela Fundação Peseu Abramo e o Instituto Rosa Luxemburgo em 2008 revelou grupos aos quais os brasileiros sentem sentimentos de repulsa, ódio, antipatia e congêres, tendo ficado em primeiro lugar os ateus, com $42 \%$ de aversão, e em segundo lugar os usuários de drogas, com $41 \%$ (FUNDAÇÃO PERSEU ABRAMO, 2010, online), o que demonstra a remanescência do estigma sobre os usuários de drogas e a necessidade de realização de trabalhos para sua desconstrução.
} 
10.216/2001 para considerar a dependência química como transtorno mental (REHFELDT, 2013).

No plano das capacidades, a consideração da dependência química como transtorno mental torna os dependentes, nos termos do art. $4^{\circ}$ do Código Civil, inciso II, relativamente incapazes a determinados atos ou à maneira de os exercer. Nesta linha de raciocínio, a internação sem consentimento aí encontra seu fundamento jurídico, na limitação da autonomia do doente mental e na possibilidade de submetê-lo à decisão de terceiro sobre qual é o melhor tratamento a ser perseguido, tendo em vista ainda o princípio bioético da proteção.

Apesar de seu fundamento jurídico válido no ordenamento brasileiro, a internação sem consentimento como modelo de tratamento encontra opositores no que se refere à legalidade e até mesmo à constitucionalidade. Entre as razões, se encontram os argumentos acerca de ofensa à autonomia da vontade do paciente quanto à escolha de seu tratamento e, ainda, sua liberdade, em vista da própria Lei $\mathrm{n}^{\circ}$ 11.343/2006, a atual Lei de Drogas, ter despenalizado o crime de uso de drogas em seu art. 28, não the imputando pena de prisão, enquanto sob a pretensão de "tratamento forçado" o poder público tem a possibilidade de enclausurá-lo, sob fundamentos jurídicos que podem esconder pretensões higienistas (REHFELDT, 2013).

A internação psiquiátrica, nos termos do art. $4^{\circ}$ caput e $\S^{\circ} \stackrel{\circ}{\text { da }}$ Lei $n^{\circ}$ 10.216/2001, consiste em tratamento excepcional destinado ao portador de transtorno mental, cabível somente na falha de tratamentos ambulatoriais. Trata-se de enclausuramento em estabelecimento psiquiátrico, com fins de cuidados intensivos e reinserção social do paciente, conforme o referido artigo.

Quanto à indispensabilidade de prévio tratamento extra hospitalar prevista no art. $4^{\circ}$ caput da Lei ํo 10.216/2001, é jurisprudência firmada perante o Superior Tribunal de Justiça (2014) que a mera demonstração de insuficiência do tratamento ambulatorial frente à gravidade do caso já é bastante para o cabimento da medida excepcional de internação, tendo o entendimento da corte mitigado o texto da lei. Consoante a este entendimento é a jurisprudência do Tribunal de Justiça do Estado do Tocantins (2015). 
Sua cessação se dará com a requisição daquele que a solicitou, ou com o aval

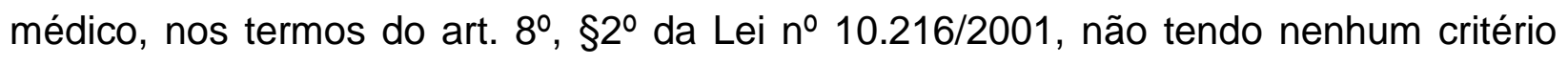
objetivo sido estabelecido em lei como autorizador da cessação da internação, bastando o requerimento de algum legitimado (BARROS; SERAFIM, 2009). Ressalvese, no entanto, a possibilidade do médico negar a alta em caso de iminente risco de vida, nos termos do art. 22 do Código de Ética Médica (CONSELHO FEDERAL DE MEDICINA, 2009).

Nos termos do art. 6º, parágrafo único da Lei ํㅜ 10.216/2001, as internações psiquiátricas se classificam-se em 1) Voluntária; 2) Involuntária; 3) Compulsória.

A internação voluntária é aquela em que o paciente consente com o tratamento de internação, assinando termo de livre consentimento esclarecido de que deseja se submeter à ele. A internação involuntária consiste em modalidade que dispensa 0 consentimento do paciente para sua instituição, consistindo seu pedido em um procedimento administrativo de solicitação de internação, em estabelecimento público ou particular que ofereça o tratamento de desintoxicação.

A legitimidade passiva para seu pedido é controversa, mas é comumente aceita por parte da família ou o próprio Ministério Público, Defensoria Pública, ou ente público responsável. A controvérsia acerca da legitimidade na internação involuntária reside na legitimidade extraordinária daqueles que não são parentes, por se crer que a modalidade involuntária existe com o requisito do consentimento familiar.

A internação compulsória é a intervenção do poder público sem consentimento que ocorre em razão da gravidade do caso tê-lo tornado questão de saúde pública, e não haver solicitação de familiar para a internação. A modalidade compulsória existe justamente para que a justiça suprima o consentimento familiar e daquele que não mais responde por si. Existe, contudo, relevante controvérsia acerca deste conceito, pois conforme apresenta o Ministério da Saúde (BRASIL, 2015) e o Ministério Público Federal, por meio da Procuradoria Federal dos Direitos do Cidadão (2011), a internação compulsória é somente a medida de segurança internativa, sendo ilegal a determinação judicial de internação em qualquer outro contexto. 
Portanto, torna-se claro que a Lei oㅜ 10.216/2001 não esclareceu a situação da qual decorreria a decisão judicial autorizadora da internação compulsória, existindo importante lacuna na norma. Percebe-se que a omissão da lei em comento está sendo suprimida e integrada, nos termos do art. $4^{\circ}$ da Lei de Introdução às Normas do Direito Brasileiro, Decreto lei no 4.657/1942, por analogia à internação involuntária, a qual torna cabível a internação sem consentimento por meio de solicitação dos legitimados, aliada à comprovação do estado de dependência química.

Reconhece o Ministério da Saúde (BRASIL, 2015) que sua compreensão é contra-hegemônica no sistema de saúde e de justiça, devendo ser buscada a sua construção e implantação pelos gestores.

No entanto, conforme aceito amplamente na prática judiciária, tanto os legitimados do art. 747, Código de Processo Civil (2016), quanto o poder público podem formular ao judiciário o pedido de internação do paciente, em razão de mera questão de não previsão expressa da totalidade dos legitimados processuais ser visto como uma limitação burocrática à efetivação do direito material à saúde daquele que necessita do tratamento, tendo ainda em vista o art. 196 da Constituição Federal o qual preceitua o direito universal à saúde, e o dever de todos os entes federativos de efetivá-lo.

Compreendem no mesmo sentido pela amplitude dos legitimados ativos as jurisprudências do Tribunal de Justiça do Estado do Tocantins (2014a, 2014b), Tribunal de Justiça do Rio Grande do Sul (2012), Tribunal de Justiça do Maranhão (2012), Tribunal de Justiça de Minas Gerais (2012), Tribunal de Justiça de São Paulo (2014).

Ressalta-se que constituem o recorte do presente trabalho as modalidades de internação involuntária e compulsória, as quais dispensam o consentimento do dependente químico. Com base no exposto, passa-se à apresentação dos parâmetros impostos pela Lei oㅜ 10.216/2001 que foram observados na pesquisa, no que se refere aos procedimentos de internação e requisitos mínimos do estabelecimento:

A) Procedimento legal de internação: 
A internação involuntária, que constitui em procedimento administrativo, possui, sinteticamente, o seguinte procedimento legal, nos termos da Lei $\mathrm{n}^{0}$ 10.216/2001:

1) Falha no tratamento ambulatorial (Lei $n^{\circ}$ 10.216/2001, art. $4^{\circ}$, caput);

2) Requisição da internação por terceiro interessado (Lei $n^{\circ} 10.216 / 2001$ art. $6^{\circ}$, $2^{\circ}$ ) junto ao estabelecimento de saúde;

3) Autorização de médico cadastrado junto ao CRM da região do estabelecimento (Lei no 10.216/2001, art. 8º);

4) Internação involuntária;

5) Comunicação da internação involuntária ao Ministério Público Estadual e à Comissão Revisora das Internações Psiquiátricas Involuntárias em até 72 horas (Lei ํo 10.216/2001, art. $\left.8^{\circ}, \S^{\circ}{ }^{\circ}\right)$;

6) Término da internação (Lei oํ 10.216/2001, art. $8^{\circ}$, $\S^{2}{ }^{\circ}$ ).

A internação compulsória, por sua vez, constitui em procedimento judicial, cujo procedimento legal se encontra insculpido no, e sumariamente consiste em:

1) Falha no tratamento ambulatorial (Lei ํㅜ 10.216/2001, art. 4ํㅜ caput); Proposição de internação compulsória pelos legitimados ativos (Lei nำ 10.216/2001, art. 9ํ). Documento obrigatório: Autorização de médico cadastrado junto ao CRM da região do estabelecimento (Lei oㅜ 10.216/2001, art. 8ㅜ)

2) Deferimento do pedido de internação compulsória;

3) Internação compulsória;

4) Comunicação da internação compulsória ao Ministério Público Estadual e à Comissão Revisora das Internações Psiquiátricas Involuntárias em até 72 horas (Lei no 10.216/2001, art. $\left.8^{\circ}, \S^{\circ}{ }^{\circ}\right)$;

5) Término da internação (Lei oํ 10.216/2001, art. 8으, §2º);

B) Requisitos mínimos para a existência das clínicas: 
De acordo com a Lei ํㅜ 10.216/2001 (art. 4ํㅗㅇํํ), é vedada a internação psiquiátrica em instituições sem o mínimo existencial digno para o paciente. A lei descreve as características de instituição de aspecto asilar da seguinte forma:

1) Instituições desprovidas dos recursos do art. $4^{\circ}, \S^{\circ} 2^{\circ}$ :

- Serviços médicos; Assistência social; Psicológicos; Serviços ocupacionais; Serviços de lazer; Outros serviços adequados às finalidades declaradas do $\S 10$ : a reinserção social do paciente em seu meio;

2) Instituições que não assegurem os direitos do art. º, parágrafo único:

- Ter acesso ao melhor tratamento do sistema de saúde, consentâneo às suas necessidades; Ser tratada com humanidade e respeito e no interesse exclusivo de beneficiar sua saúde, visando alcançar sua recuperação pela inserção na família, no trabalho e na comunidade; Ser protegida contra qualquer forma de abuso e exploração; Ter garantia de sigilo nas informações prestadas; Ter direito à presença médica, em qualquer tempo, para esclarecer a necessidade ou não de sua hospitalização involuntária; Ter livre acesso aos meios de comunicação disponíveis; Receber o maior número de informações a respeito de sua doença e de seu tratamento; Ser tratada em ambiente terapêutico pelos meios menos invasivos possíveis; Ser tratada, preferencialmente, em serviços comunitários de saúde mental.

Da exposição do procedimento legal de internação e dos requisitos legais mínimos dos estabelecimentos de internação, emergiram diversos requisitos para que a internação se travista de legalidade. Em todas as modalidades internativas são requisitos essenciais indispensáveis ao ato da internação a falha no tratamento ambulatorial e a comunicação ao Ministério Público ou à Comissão Revisora do acontecimento da internação em até 72 horas. Já no que se refere à internação compulsória, é necessária ainda a determinação judicial da internação. Para todas as modalidades de internação, indiscriminadamente, o estabelecimento possui as mesmas exigências de padrão mínimo de dignidade, no que se refere à sua infraestrutura, prestação de serviços e tratamento do paciente. 
Desta forma, é notável da exposição dos fundamento jurídicos que subsidiam a internação psiquiátrica não consentida, que estes argumentos se encontram apaziguados na prática jurídica, restando ainda, no entanto, discussões na seara acadêmica acerca de sua constitucionalidade e legalidade no que refere à aplicação extensiva à dependência química.

\section{INTERNAÇÕES NÃO CONSENTIDAS NO ESTADO DO TOCANTINS}

Neste momento da pesquisa, observou-se como as internações sem consentimento foram desenvolvidas no Estado a partir da descrição dos dados indicados pelos documentos a seguir descritos e, posteriormente, passou-se à análise crítica dos mesmos, sob a perspectiva da Lei ํㅜ 10.216/2001.

No Estado do Tocantins, os principais órgãos atuantes são a Secretaria Estadual de Saúde - SESAU e o Conselho Estadual Sobre Drogas do Estado do Tocantins CONESD. A SESAU constitui órgão da administração direta do estado, cuja responsabilidade consiste na promoção de políticas públicas saúde em aspecto amplo. Já o CONESD, órgão vinculado à Secretaria de Cidadania e Justiça, nos termos do Decreto $n^{\circ} 4.604$, de 02 de agosto de 2012 (TOCANTINS, 2012), é o órgão superior do Sistema Estadual de Políticas sobre Drogas, com competências descritas no art. $4^{\circ}$ do referido ato normativo, as quais podem ser resumidas na orientação acerca das políticas públicas estaduais sobre drogas, estratégias para sua execução, e integração com órgãos assemelhados.

Constituem o Sistema Estadual de Políticas sobre Drogas, nos termos do art. 2o do Decreto $n^{\circ}$ 4.604, o Conselho Estadual sobre Drogas, Superintendência de Ações sobre Drogas, conjunto de órgãos e entidades da Administração Pública (principalmente os Municípios e a Superintendência Regional da Polícia Federal no Tocantins) e entidades da sociedade civil das áreas da atenção à saúde e da assistência social que atendam aos usuários ou dependentes de drogas e seus familiares. 
Em razão da inexistência de clínica pública que promova o tratamento de internação e desintoxicação no Estado do Tocantins, encontrava-se em trâmite, no período da pesquisa, o Projeto de Lei Estadual no 91/2011 com tal objetivo, e fora firmado TAC - Termo de Ajuste de Conduta em 2012 entre o Ministério Público e a Defensoria Pública com o Executivo Tocantinense, fixando a responsabilidade estatal de custear este tratamento através das instituições particulares que fornecem este tratamento a todo paciente assistido pelos Centros de Atenção Psicossocial - CAPS em âmbito municipal aos quais for recomendado o tratamento de internação, com ou sem consentimento (COSTA, B. C., 2017).

Segundo Costa (B. C. 2017, p.4), coordenador junto ao Centro de Referência em Assistência Social de Colinas do Tocantins, o TAC vem sendo descumprido sob a alegação financeira da reserva do possível impossibilitar o tratamento psiquiátrico adequado, fazendo com que o paciente se submeta ao tratamento não recomendado, puramente ambulatorial, ou, quando determinada a medida de segurança por cometer atos criminosos, cumprir a sanção em cela de cadeia, quando esta deveria ser cumprida em clínica especializada.

Segundo informações de 2014 da Secretaria de Saúde do Estado do Tocantins, por meio do jornal Conexão Tocantins (2014, online), o Estado possuía 17 CAPS, sendo 3 destes do tipo CAPS AD, modalidade especializada em atendimento de pacientes com problemas com drogas. Em 2009, havia apenas 10 CAPS no Estado (CONEXÃO TOCANTINS, 2009, online). Nota-se que a quantidade de CAPS entre os anos de 2009 e 2014, aumentou em 70\%, trazendo maior cobertura e assistência à rede ambulatorial do estado.

Em 2016 o Estado do Tocantins possuía convênio com somente uma clínica (realizadora tanto de procedimentos de internação voluntária quanto involuntária e compulsória), a Comunidade Terapêutica Clínica Fênix Renovando Vidas ("Clínica Fênix"), cuja sede administrativa se encontrava em Palmas - TO, e a clínica na Chácara Rancho Fundo em Luzimangues - TO, distrito de Porto Nacional - TO.

Por meio de levantamento documental obteve-se acesso a relatórios de inspeções à referida clínica realizadas pelas seguintes instituições: Núcleo de Defesa a 
Saúde da Defensoria Pública do Estado do Tocantins (NUSA-DPE-TO), Conselho Estadual sobre Drogas do Tocantins (CONESD-TO) e Conselho Regional de Medicina do Estado do Tocantins (CRM-TO), e o Inquérito Civil no 18/2016 do Ministério Público Estadual realizado pela $7^{\mathrm{a}}$ Promotoria de Justiça da Comarca de Porto Nacional, os quais averiguaram e constataram irregularidades de infraestrutura e condução dos procedimentos de internação.

Quanto às inspeções empreendidas pela DPE-TO, uma se deu em 20 de janeiro de 2013 e foi realizada pelo Defensor Público e Analista Judiciária, acompanhados de 2 sócios proprietários, e em 09 de julho 2015 houve reiteração da inspeção, com a presença de 3 Analistas Jurídicos, uma Psicóloga, uma Jornalista e um Motorista, em razão da existência de procedimento interno de atendimento nº 7/2015 que denunciava maus-tratos.

Já a inspeção empenhada conjuntamente pelo CONESD e CRM-TO, a qual ocorreu de forma não previamente comunicada ("surpresa"), em 19 de setembro de 2016, e se dera com a presença do Vice-Presidente do CONESD, Promotor do MPETO, Psicólogo representante do Conselho Regional de Psicologia, Médico representante do Conselho Regional de Medicina, Delegado da Polícia Federal e dois Agentes de Polícia.

Em 2016, o MPE-TO, por meio da $7^{\text {a }}$ Promotoria de Justiça da Comarca de Porto Nacional, instaurou o Inquérito Civil Público № 18/2016 para investigação das supostas irregularidades. Este órgão informou que até o momento de instauração do Inquérito Civil, nenhuma comunicação formal havia sido feita pelos Conselhos profissionais de Medicina, Farmácia ou Enfermagem, até serem requisitados (MPE-TO, 2016, p. 27), situação que permitiu a manutenção por tanto tempo das irregularidades do referido estabelecimento.

Todos os relatórios apresentaram impressões semelhantes. Quanto à duração, fora informado que o tratamento de terapia duraria 1 (um) ano, consistindo em 6 (seis) meses de internação, podendo se estender por, no máximo, mais 2 (dois) meses, e ainda mais 6 (seis) meses em ressocialização, período no qual o paciente retornaria à clínica quinzenalmente para acompanhamento (DPE-TO, 2013, p.04). 
No que se refere à abordagem psicoterápica, era utilizado o método minnesota/12 passos (DPE-TO, 2013, p.03), como método terapêutico informal, de caráter de autoajuda motivacional e espiritual para a desintoxicação, por meio do seguimento de 12 passos os quais voltam-se ao desenvolvimento da espiritualidade e responsabilidade.

O valor do tratamento individual fixado através do convênio com o Estado era uma mensalidade de $R \$ 2.880$ (dois mil e oitocentos reais), inclusa a medicação, pelo período da internação, até 8 meses, estando incluso nas parcelas o valor do acompanhamento pós internação, não estando incluso o serviço de resgate/busca do paciente e condução até a clínica, tendo sido determinada a responsabilidade da família apresentá-lo (DPE-TO, 2015, p.05). Contudo, fora verificado na análise dos documentos que os proprietários da clínica relataram que desde antes da instituição do convênio para internação compulsória decorrente do judiciário tocantinense, o Estado do Tocantins se encontrava inadimplente quanto ao pagamento dos serviços avulsos, e continuou inadimplente desde a fixação do convênio (DPE-TO, 2015. p.05).

Quanto ao número de pacientes, em 2013 a clínica possuía 25, exclusivamente homens, dos quais 20 adultos e 5 menores de idade (DPE-TO, 2013, p.05). Durante a vistoria realizada em 2015 se verificou a existência de 64 pacientes, sendo 43 homens adultos, 13 mulheres adultas, 5 meninos e 3 meninas (DPE-TO, 2015, p.03), e cujas idades variavam entre 13 e 58 anos, majoritariamente internados de modo compulsório (DPE-TO, 2015, p.06). Em outubro de 2016 a clínica possuía 23 pacientes, entre homens adultos e meninos (em quantidade não especificada de cada grupo), tendo a ala feminina sido fechada (CRM-TO, 2016, p.04; CONESD, 2016, p.01). Em todos as averiguações o número de paciente estava condizente com a capacidade de lotação.

Quanto às mulheres, restou comprovado que elas enfrentaram problemas particulares em razão de sua condição e a construção posterior da sua ala. Originalmente a clínica fora desenhada para recebimento somente de pacientes homens, não recebendo mulheres pela ausência de espaço destinado a elas, até o momento em que o espaço da clínica foi repartido e criada ala especial destinada ao recebimento de pacientes do sexo feminino. A existência da nova ala foi identificada 
em 2015, não tendo sido informado o momento de sua implantação (DPE-TO, 2015, p.03 e 06).

Em razão desta repartição do espaço entre alas feminina e masculina, a ala masculina ficou privilegiada em relação à das mulheres, pois a área masculina possuía infraestrutura para lazer variado (campo de futebol, vôlei de areia, acesso ao lago) e a feminina não contava com estrutura planejada para o lazer, mas somente espaço aberto sem qualquer suporte (DPE-TO, 2015, p.03). Fora informada, ainda, a ausência de acompanhamento ginecológico às mulheres (DPE-TO, 2015. p.07-08).

Em 2013 durante a inspeção da DPE-TO, fora constatado o fornecimento de educação básica aos menores, tendo sido verificada sua permanência na inspeção de 2015 (2013, p.07; 2015, p.06). Já em 2016, fora informada a ausência de atividade profissionalizante ou educacional, tanto para os adultos quanto menores de idade (CONESD, 2016, p.03; CRM-TO, 2016, p.04).

Assim como os pacientes adultos, os menores também relataram ter presenciado e sofrido agressões físicas por parte da equipe da clínica, e sua convivência se dava no mesmo espaço que os adultos (CONESD, 2016, p.01-02; CRM-TO, 2016, p.04). Conforme o MPE-TO, a clínica jamais teve condições de receber crianças e adolescentes, tendo estes sido entregues aos juízos responsáveis assim que recomendado pela Promotoria da Infância e Juventude (MPE-TO, 2016, p.27).

Os relatórios não trazem descrições de elementos de etnia, cor ou classe social dos internados, ficando tais recortes impossibilitados pela ausência de dados.

Acerca da alimentação, noticiou o relatório da DPE-TO que, em 2013, havia nutricionista a serviço da clínica (DPE-TO, 2013, p.08); no entanto, em 2015 fora observada a ausência de profissional de nutrição, a deficiência alimentar, e a repetitividade do cardápio em bolachas de água e sal e suco em pó (DPE-TO, 2015, p.08). De igual maneira se manteve até a nova inspeção em 2016, no qual as reclamações dos pacientes quanto à alimentação foram reiteradas, tendo sido verificada a ausência de acompanhamento nutricional nas refeições, as quais se encontravam repetitivas em frango e salsicha (CONESD, 2016, p.03) 
No que se refere ao tratamento dispensado aos pacientes, emergiram diversos relatos por parte dos internos quanto à prática corriqueira de agressões físicas por parte do coordenador e monitores da Clínica Fênix, até mesmo contra os pacientes menores de idade (CONESD, 2016, p.01-02). No momento da inspeção, um paciente apresentara lesões indiciárias de agressão (MPE-TO, 2016, p.14).

Emergira ainda dos relatórios a notícia do falecimento do paciente E. F. A. V. (33 anos), dentro da clínica. As averiguações quanto ao óbito inidentificaram em seu registro a administração de remédios e utilização de contenção física sem recomendação médica. Os internos apontaram a omissão de socorro por parte da clínica ao paciente que veio a falecer (CRM-TO, 2016, p.05). Fora informado pelo MPETO que vinha sendo investigada criminalmente a prática de tortura no dentro do estabelecimento (2016, p.08).

Fora relatada, ainda, a obrigatoriedade de participação em todas as atividades da Clínica, sem possibilidade de escusa religiosa ou ideológica do paciente, sob penas de suspensão de visita, proibição da ligação semanal, e imposição de tarefas braçais de limpeza (carpir e lavagem de panelas), contudo, inexistiam atividades profissionalizantes ou educacionais, para maiores ou menores, havendo somente a "laborterapia" (CONESD, 2016, p.03; MPE-TO, 2016, p.29). A laborterapia consistia em atividade de limpeza do pátio, roupas e utensílios pessoais e da clínica por parte dos pacientes. No mesmo sentido, reiterou a DPE que a limpeza era obrigação dos internos, sob o argumento de laborterapia (DPE-TO, 2015, p.03 e 07), não podendo desta se escusarem os pacientes, sob pena de privação de direitos à visitas, telefonemas e isolamento (proibição de comunicação com os demais pacientes) (DPETO, 2015, p.04).

Quanto ao direito à visita, emerge dos relatórios que este era concedido somente após 60 dias de internação (período de incomunicabilidade), a partir de quando poderia recebê-las mensalmente, até 5 familiares por vez. A comunicação via telefonema também se submetia ao período de 60 dias de incomunicabilidade, a partir de quando poderiam ser realizadas mensalmente, sob vigia de funcionários (DPE-TO, 2013, p.05). Destaca-se que o direito a visitas ainda era condicionado ao 
comparecimento nos encontros do Programa Familiar e grupos de mútua ajuda (DPETO, 2013, p.05), e o acesso a comidas individuais, roupas e pertences próprios controlado por horário e vigilância da clínica (DPE-TO, 2015, p. 04).

No que tange à infraestrutura para o recebimento dos pacientes e a organização clínica, diversas irregularidades foram constatadas. O CRM-TO concluiu pela ausência de aparelhos essenciais conforme as normas sanitárias, bem como inexistência ou inconformidade de espaços conforme as normas sanitárias e código de ética, ainda a insuficiência de funcionários da área da saúde para acompanhamento dos pacientes e da medicação.

Em novembro de 2016, o Corpo de Bombeiros identificou a ausência de projeto contra incêndio e pânico (MPE-TO, 2016, p.01). Verificou-se que cada alojamento possuia um sanitário, tendo o CRM-TO declarado que o mesmo se encontrava em "péssimas condições de funcionamento, higiene e estrutura física", assim como os dormitórios e chuveiros (2016, p.03-04).

Fora informado pelo MPE-TO (2016, p.02) as más condições dos alojamentos, suas paredes, ausência de registros que comprovem a limpeza e desinfecção semestral de reservatórios de água, e o vencimento dos registros de controle trimestral de água e registro de controle de pragas e vetores. Quanto aos chuveiros, fora noticiado pelo relatório da DPE-TO a ausência de suporte da caixa d'água da clínica para a quantidade de pacientes, o que vinha a causar intrigas na hora do banho (2015, p.08).

Fora notificada a ocorrência de rebelião na clínica em 24 de julho de 2016 por razão dos maus-tratos e utilização de amarras, tendo como estopim a aplicação forçada do medicamento haldol em um paciente (MPE-TO, 2016, p.07-08 e 16). O COREN-TO informou irregularidades como ausência de responsável técnico para enfermagem, ausência de instrumentos organizacionais, enfermeiros no período noturno e final de semana, incompletude dos registros de enfermagem. (MPE-TO, 2016, p.03-05)

Registrou o CRM-TO não ter encontrado qualquer Termo de Consentimento Livre Esclarecido - TCLE dentro da clínica (CRM-TO, 2016, p.02), e ter encontrado em 
verificação aos documentos médicos, prontuários com informações precárias e incompletas, incapazes de prestarem à sua finalidade (CRM-TO, 2016, p.02-03). Exemplificativamente, os prontuários não indicam o diagnóstico, prognóstico, conduta, história pessoal ou familiar, queixas do paciente, estado mental, não apresentam sequer letra legível para maior compressão de seu conteúdo, entre outras insuficiências (CRM-TO, 2016, p.04).

Não constava ainda qualquer notificação de internação sem consentimento ocorrida no ano de 2016, conforme constatado por certidão no Inquérito Civil, e confirmado pelo próprio sócio da clínica em audiência ministerial (MPE-TO, 2016, p.01 e 07).

Além do já descrito, a maioria dos pacientes internos relatam nunca terem sido atendidos pelo médico psiquiatra, tendo ainda sido verificada disparidade entre a letra e assinatura do médico psiquiatra nos prontuários (CRM-TO, 2016, p.04-05), fato que se correlaciona com a prática notada pelo COREN-TO de "prescrição médica à distância" (MPE, 2016, p.04), situação em que o enfermeiro comunica o estado do paciente ao médico, o qual está em outro local, e administra o prescrito à distância. Verificou-se ainda, por meio do relatório da DPE-TO, a ausência de atendimentos de problemas de saúde corriqueiros/diários, como febres, dores de dente e barriga, devido à enfermaria estar fechada, a ausência de tratamento odontológico aos pacientes, e a ultrapassagem do prazo de internação determinado em contrato aos menores (2015, p.07-08). Fora recomendado pelo CRM-TO o encaminhamento do relatório à sua corregedoria para a apuração de possíveis infrações éticas ocorridas no estabelecimento (MPE-TO, 2016, p.24).

A Vigilância Sanitária informou que o contrato firmado com o Estado do Tocantins que possibilitou a internação compulsória de pacientes por razão diversa da medida de segurança é contraditória a orientação do Ministério da Saúde, a qual compreende a internação compulsória somente em decorrência da medida de segurança (MPE-TO, 2016, p.07). 


\section{ANÁLISE SOCIOJURÍDICA DO DESENVOLVIMENTO DAS INTERNAÇÕES SEM CONSENTIMENTO NO ESTADO DO TOCANTINS}

As comunidades terapêuticas que fornecem serviços de natureza clínica e de assistência à saúde, devem seguir não só as normas da Resolução n 29/2011 da Agência Nacional de Vigilância Sanitária (a qual dispõe sobre requisitos de segurança sanitária para o funcionamento de estabelecimentos que prestem assistência à pessoas com transtornos decorrentes de substâncias psicoativas), como ainda as normas sanitárias relativas a estabelecimentos de saúde, como era o caso da Clínica Fênix, conforme dispõe o art. $2^{\circ}$, parágrafo único da referida resolução.

No entanto, a clínica estudada, não obedecia a nenhuma destas normas, conforme averiguado por todas as instituições que inspecionaram e vistoriaram o local, como pela decisão do Inquérito Civil do MPE-TO (2016, p.07).

É notável a incapacidade do local em suportar o tratamento ao qual sua finalidade o destinava no que se refere à infraestrutura, a qual se encontrava em completo desacordo com Resolução no 29/2011 da Agência Nacional de Vigilância Sanitária quanto à Seção III - Gestão de Infraestrutura, que impõe a necessidade de instalações prediais regularizadas junto ao poder público (art. 11), instalações físicas e ambientes externos seguros e limpos (art. 12), qualidade da água (art. 13), existência de alojamento, com tamanho e aparelhamento compatível com o número de pacientes, setor de reabilitação e convivência, setor administrativo, setor de apoio logístico, e a necessidade de acessibilidade nestes espaços para portadores de necessidades especiais (art. 13, $\S^{\circ}$ ).

Conforme emergido dos fatos constatados pelos relatórios, era constante a ausência do médico psiquiatra, o não atendimento ou contato com os pacientes internados, a prescrição à distância, e administração de remédios sem a recomendação médica, claramente em desconformidade com o direito declarado no inciso V, art. 2o da Lei 10.216/2001, que afirma ser direito do paciente internado a presença médica à qualquer tempo. A prescrição à distância, administração de remédios sem recomendação médica e a precariedade dos prontuários configuram 
ainda em inconformidades com a Resolução n 29/2011 da Agência Nacional de Vigilância Sanitária, na forma, art. $7^{\circ}$, que proíbe tais condutas, bem como normativas próprias do CRM e COREN.

$\mathrm{O}$ relato de não encontro de qualquer Termo de Consentimento Livre e Esclarecido - TCLE no estabelecimento é outra irregularidade grave pois é documento indispensável à aferição do consentimento e esclarecimento do paciente quando ao tratamento de internação ao qual voluntariamente se submete. Conforme já exposto, o convênio da clínica com o Estado do Tocantins era destinado ao recebimento de pacientes para tratamentos de internação voluntária e involuntária. A importância deste documento é a garantia documental da concessão do consentimento dos voluntariamente internados, a assegurar que se submeteram livremente ao tratamento, bem como que não poderiam ser internados sem procedimento administrativo ou judicial que suprimisse $\mathrm{o}$ seu consentimento, nos termos do art. $7^{\circ}$ da Lei $n^{\circ}$ $10.216 / 2001$.

Outra irregularidade constatada fora a ausência de comunicação ao Ministério Público das internações realizadas por todo ano de 2016, contrariando art. 8ํㅗㅇ §1 Lei no 10.216/2001, item obrigatório para que o Ministério Público desenvolva acompanhamento e fiscalização das internações e regularidade das mesmas. Tal fato somado à não comunicação dos conselhos profissionais de saúde das irregularidades há tempos constatadas e não corrigidas pela Clínica Fênix ao Ministério Público, possibilitou o funcionamento irregular da clínica e utilização de procedimentos inadequados por longo tempo.

Quando às agressões contra os pacientes maiores e de sobremaneira contra os menores, ferem diretamente os direitos do art. $2^{\circ}$, incisos II e III da Lei 1 no 0.216/2001 que abrangem aspectos genéricos de dignidade no tratamento a ser dispensado ao paciente em tratamento, que são os direitos de tratamento com respeito e humanidade, com finalidade de recuperação e reinserção social, e ainda o direito de proteção contra abusos e explorações. É ainda direito do paciente ser tratado pelos meios menos invasivos possíveis (art. 2o da Lei № 10.216/2001), configurando as atitudes violentas 
para aplicação de medicamentos e manutenção da ordem dentro da clínica em postura arbitrária e incoerente com a ordem jurídica e a própria ética profissional.

Fora ainda informado que o tratamento dos menores tinha excedido o tempo limite máximo estipulado em contrato (DPE-TO, 2015. p.08). Conforme o art. 9º, inciso Il da Portaria 3.088/2011 do Ministério da Saúde, as comunidades terapêuticas clínicas somente podem realizar a internação pelo prazo máximo de 9 (nove) meses para paciente adulto. Não foi possível extrair da análise documental as informações que se referem ao tempo máximo estabelecido em contrato para internação dos menores e em quanto tempo estava sendo excedido.

$\mathrm{Na}$ referida clínica, a comunicação era restrita durante 1/3 (um terço) da internação (60 dias), não podendo o paciente se comunicar com a família por visitas ou telefonemas, claramente em desacordo com o art. $2^{\circ}$, VI da Lei $n^{\circ}$ 10.216/2001, que preconiza o direito do paciente ter livre acesso aos meios de comunicação disponíveis. Tal direito de comunicação ainda poderia ser suspenso caso o paciente se negasse participar da laborterapia, vindo a não ter temporariamente acesso a telefonemas, visitas, e até mesmo proibição de interagir e conversar com os demais pacientes.

A suspensão do direito de comunicação também não coaduna com a finalidade de reinserção social do tratamento internativo em tela e nem com o tipo de estabelecimento como é a Comunidade Terapêutica (art. 1ํㅡㄹ parágrafo único da Resolução n² 29/2011 da Agência Nacional de Vigilância Sanitária), pela qual se busca tratamento em âmbito comunitário com fins de ressocialização, ferindo ainda o art. 20 da mesma resolução, ao impor penalidade de caráter psíquico (incomunicabilidade).

No que se refere à laborterapia, esta era realizada como atividade ocupacional obrigatória aos pacientes, a qual consistia em serviços de limpeza do estabelecimento, roupas e utensílios. É notável o caráter de utilização da mão de obra dos internos para realização de serviços essenciais da clínica, como limpeza e alimentação, a fim de reduzir os custos finais do empreendimento, o que se confirma por não possuírem auxiliares de serviços gerais, nem existirem oficinas de aprendizagem técnica ou profissional. 
É proibida a internação psiquiátrica em estabelecimento de características asilares, que, de acordo com a Lei n 10.216/2001 são justamente aquelas desprovidas dos recursos do art. $4^{\circ}$, $\S^{2^{\circ}}$, que são serviços médicos, assistência social, psicológicos, serviços ocupacionais, serviços de lazer, entre outros serviços adequados às finalidades de a reinserção social do paciente. Ainda de acordo com a Lei no 10.216/2001, são também características asilares o não asseguramento dos direitos do art. $2^{\circ}$, parágrafo único, exemplificativamente, o direito ao tratamento com humanidade, livre acesso à comunicação, presença médica, acesso ao melhor tratamento disponível ao seu caso, entre outras.

Regionalmente, conforme ficou demonstrado da análise documental, a fiscalização quanto ao funcionamento dos estabelecimentos de internação é demasiadamente falha, a qual permitiu que uma instituição irregular desde seu surgimento, há anos, não só permanecesse funcionando, como ainda fixasse convênio com o Estado e recebesse pacientes enviados às suas custas.

Conforme podemos aferir do constatado do ambiente da clínica estudada, continha diversas das características manicomiais estabelecidas em critério legal. $O$ mesmo fora notado no Inquérito Civil do Ministério Público, o qual alegou que o tratamento da clínica dispensado aos seus pacientes remonta às "práticas de antigos manicômios" e fora norteada por puro "empirismo", em razão no notório descumprimento de normas sanitárias e da própria Lei Antimanicomial (MPE-TO, 2016, p.27-29).

Conforme Duarte (2015), a política pública que promove internações forçadas está a ampliar leitos psiquiátricos em instituições fechadas, reforçando a estigmatização e institucionalização a qual pretendia-se extirpar com a Reforma Psiquiátrica. No Estado do Tocantins, como se observa, foi notável no período em análise o desenvolvimento de uma política pública com apreço pelo tratamento no modelo de internações, consentidas ou não. Emergiu ainda dos dados revistos a falta de comunicação dos tratamentos internativos com a rede de apoio, e ausência de trabalho com intersetorialidade, na forma da promoção de cursos profissionalizantes, lazer, atividades educacionais, entre outras possibilidades. 
Em razão disso, observou-se ainda na clínica estudada a característica de instituição total e a não observância ao princípio da incompletude institucional, por ter reduzido todas as suas atividades ao seu próprio estabelecimento e tratamento medicamentoso, sem utilização de meios diversos no tratamento, não ofertando perspectivas e possibilidades ao internado que o desenvolvessem pessoalmente ou profissionalmente.

De igual maneira, o sistema judiciário tocantinense ao determinar a não necessidade prévia de interdição para a internação psiquiátrica bem como ao mitigar a necessidade de prévia tentativa de tratamento extra hospitalar, está a precarizar a medida internativa, tirando-a de seu patamar de excepcionalidade e a colocando em lugar de destaque no tratamento da dependência química, em direção diametralmente oposta aos fundamentos da Lei no 10.216/2001 e do movimento que a originou.

O procedimento de curatela é justamente o meio pelo qual se verificará as limitações cognitivas e de volição do indivíduo a fim de verificar quando sua capacidade precisa ser suprimida ou apenas complementada, em avaliação multidisciplinar, imprescindível para se averiguar a capacidade civil do sujeito. Dispensar a curatela é permitir que somente o laudo médico subsidie o pedido de internação, o qual, limitado à sua área de conhecimento, não é capaz de verificar os limites da capacidade civil tão minunciosamente quanto uma equipe multidisciplinar, a qual contaria, exemplificativamente, com conhecimentos da assistência social, psicologia, enfermagem, pedagogia, entre outras áreas. Portanto, não deve o complexo procedimento de curatela e interdição ser substituído por mero pedido de internação subsidiado por somente laudo médico.

De igual maneira, tem-se mitigado o texto expresso da lei que determina a necessidade de prévio tratamento ambulatorial. Tem-se que, de fato, justificativa desta exceção mediante situação de concreto perigo de vida acompanhada com a negativa do sujeito de se submeter ao tratamento extra hospitalar. Afora esta situação acima mencionada, a dispensa de prévia tentativa de tratamento por meio da rede assistencial constituirá, novamente, em inversão dos princípios declarados da Lei no 
10.216/2001, a qual desencoraja a medida internativa e privilegia o acolhimento por meios extra hospitalares.

A observação destes requisitos visam assegurar que a internação seja o mais garantista possível, diminuindo-se o grau de discricionariedade por meio de formalidades imprescindíveis, as quais constituem, em verdade, garantias do sujeito de que este terá satisfeito um devido processo legal na aferição de sua capacidade e escolha de melhor tratamento para si.

Alerta Worm (2017) que as internações psiquiátricas, de sobremaneira as sem consentimento, demandam especial atenção do estado para que não se reproduzam prática manicomiais de maus tratos, devendo ser encaradas como medidas excepcionais em detrimento ao tratamento ambulatorial.

Percebe-se, no entanto, que tal atenção e cuidado não foi, por longo tempo, dispensada pelo Estado do Tocantins aos seus cidadãos, tendo suas condutas e omissões permitido que estruturas asilares se reproduzissem, ainda mais com clínica conveniada.

O Inquérito Civil Público nº 18/2016 da 7ª Promotoria de Justiça da Comarca de Porto Nacional em sua decisão de 07 de novembro de 2016 recomendou à Clínica Fênix que efetuasse as correções de todas suas irregularidades elencadas, cada uma em um prazo determinado (MPE-TO, 2016, p.31-37). Contudo, o estabelecimento, voluntariamente, fechou as portas em 21 de novembro de 2016.

Recentemente, em 11 de abril de 2017, em caso semelhante, a Polícia Federal apoiada pela Polícia Militar do Estado fechou a Comunidade Terapêutica Revigore, clínica particular de internação de dependentes químicos em Araguaína/TO, e veio a deter 5 (cinco) pessoas, entre funcionários e proprietário da instituição (COSTA, K, 2017). Entre as denúncias contra a Comunidade Terapêutica Revigore, estão violências físicas diversas, maus tratos, cárcere privado, e a impossibilidade de visita sem acompanhamento durante todo o tratamento. A clínica possuía 11 (onze) pacientes.

No Estado do Tocantins, segundo o Conselho Federal de Medicina (2017), perdeu-se $91 \%$ dos leitos de internação psiquiátrica, passando de 160 leitos para 15, 
entre leitos de hospitais psiquiátricos propriamente ditos assim como em hospitais gerais. Seguindo os fundamentos da Lei Antimanicomial, o Ministério da Saúde editou ainda a Portaria o 1.631/2015 determinou um percentual de 0,04 leito por 1.000 habitantes, percentual 11 vezes menor que o antigo percentual definido em 2002 pelo Minstério da Saúde pela Portaria 1.001/2002, que era de 0,45 leitos a cada 1.000 habitantes.

Destaca-se a criação o Núcleo Acolher pela Secretaria de Cidadania a Justiça do Estado do Tocantins em junho de 2016, o qual presta serviço de acolhimento, testes de doenças e triagem de pessoas com dependência química com encaminhamento ao tratamento internativo em comunidades terapêuticas (ESTADO DO TOCANTINS, 2017), o qual está a dar continuidade à prática de encaminhamento pelo Estado de dependentes químicos ao tratamento internativo, o que requer atenção por parte da sociedade civil e dos órgãos de justiça para que não se repitam falhas idênticas às constatadas no estudo do caso da Clínica Fênix.

Segundo Relatório de Atendimentos e Encaminhamentos às Comunidades Terapêuticas (2017), no ano de 2017 foram oferecidas 40 vagas para o tratamento internativo voluntário em 5 comunidades terapêuticas, sendo elas a Fazenda esperança de Porto Nacional, Lajeado e Palmas, Comunidade Leão de Judá de Palmas e Comunidade Rhema de Palmas.

O Estado do Tocantins continua a agir na prevenção e recuperação de dependentes químicos, por meio da Secretaria de Cidadania e Justiça, ao qual se vincula o Conselho Estadual sobre Drogas (CONESD) e agora a Superintendência de Ações sobre Drogas, recriada recentemente, em abril de 2017 (LIMA, 2017, online), mantendo, no entanto, política voltada à internação, a qual deveria ser encarada como medida excepcional indicada somente após o esgotamento da via extra hospitalar, nos termos da Lei no 10.216/2001. 


\section{CONSIDERAÇÕES FINAIS}

No presente artigo os objetivos principais foram desenvolver análise jurídica do tratamento da dependência química e apurar as condições do tratamento de internação psiquiátrica sem consentimento de dependentes químicos no Estado do Tocantins, de acordo com a Lei oㅜ 10.216/2001. Apesar da análise documental de relatórios dos anos de 2013, 2015 e 2016 e Inquérito Civil de 2016, não ser per si suficiente para dar conta da riqueza da realidade empírica analisada, por meio deles foi possível vislumbrar nitidamente os objetivos traçados.

Conforme dispõe o art. 4ํㅗㅇㅛ $3^{\circ}$ da Lei 10.216/2001 é proibida a internação de pacientes portadores de transtornos mentais em instituições com características asilares, e o que vem a ser tais características se encontram dispostas nos art. 2으, parágrafo único e $4^{\circ}, \S^{\circ}{ }^{\circ}$. Contudo, do que se extraiu da análise documental realizada por meio dos relatórios de inspeção da DPE-TO (2013 e 2015), CONESD (2016), CRMTO (2016) e o Inquérito Civil Público oo 18 (2016), diversas características de estabelecimento asilar foram encontrados na clínica conveniada com o Estado do Tocantins.

Chama à atenção como as políticas públicas voltadas aos dependentes químicos no Estado do Tocantins são pautadas pela precarização da internação (consentida ou não), o que é notável pela não necessidade de prévia interdição e de esgotamento da via extra hospitalar para a internação, e a prática não correspondente aos princípios e patamares mínimos declarados na Lei no 10.216/2001, situações que precisam de transformação de modo a promover a letra da lei que proconiza a internação como medida excepcional.

Apurou-se, com evidência dos dados analisados, a ausência de fiscalização quanto ao funcionamento dos estabelecimentos de internação que veio a permitir, por longo tempo, o funcionamento de clínicas irregulares incapazes de promover os objetivos do tratamento internativo e obedecer aos princípios da reforma psiquiátrica insculpidos na lei federal, sendo este outro ponto relevante que inspira urgente mudança por parte do poder executivo tocantinense. 
Vertentes do Direito

ISSN n 2359-0106

Vol. 4, n. 2, 2017.

Desta forma, a presente pesquisa, por meio da metodologia elucidada, encontrou diversas violações à Lei ํo 10.216/2001 no estudo do caso tocantinense quanto ao deselvolvimento das internações sem consentimento, propondo, como passo seguinte a ser buscado como forma de melhor atendimento aos princípios da referida lei, a revisão das estratégias de fiscalização e cobrança de resultados por meio das instituições que desenvolvam o referido tratamento, a fim de que não se repitam as falhas constatadas, bem como a melhor articulação do procedimento internativo com a rede assistencial, além do desenvolvimento de uma política pública minoritariamente voltada à internação psiquiátrica, fortalecendo-se a base na rede assistencial e intersetorialidade das instituições.

\section{REFERÊNCIAS}

AGÊNCIA NACIONAL DE VIGILÂNCIA SANITÁRIA (ANVISA). Resolução n² 29/2011. Disponível em <http://bvsms.saude.gov.br/bvs/saudelegis/anvisa/2011/res0029_30_06_2011.html>. Acesso em 10 abr. 2017.

ASSOCIAÇÃO AMERICANA DE PSIQUIATRIA. DSM V - Manual diagnóstico e estatístico de transtornos mentais. 2013. Disponível em: < http://c026204.cdn.sapo.io/1/c026204/cld-

file/1426522730/6d77c9965e17b15/b37dfc58aad8cd477904b9bb2ba8a75b/obaudoedu cador/2015/DSM\%20V.pdf>. Acesso em: 10 jan. 2017.

BARROS, Daniel Martins de; SERAFIM, Antonio de Pádua. Parâmetros legais para a internação involuntária no Brasil. Revista de Psiquiatria Clínica, v.36, n.4, p.175-177, 2009. Disponível em < http://www.scielo.br/pdf/rpc/v36n4/a08v36n4.pdf>. Acesso: 14 fev. 2017.

BRASIL. Constituição da República Federativa do Brasil de 1998. Diário Oficial da União. Brasília, DF: Senado, 1988. Disponível em:

<http://www.planalto.gov.br/ccivil_03/constituicao/constituicaocompilado.htm>. Acesso em: 10 jan. 2017.

. Decreto lei no 4.657, 04 de setembro de 1942. Lei de Introdução as Normas do Direito Brasileiro. Diário Oficial da União. Brasília, DF: Senado, 1942. Disponível em: <http://www.planalto.gov.br/ccivil_03/decreto-lei/Del4657compilado.htm>. Acesso em: 10 abr. 2017. 
. Lei no 10.216, de 6 de abril de 2001. Lei da Reforma Psiquiátrica. Diário Oficial da União. Brasília, DF: Senado, 2001. Disponível em <http://www.planalto.gov.br/ccivil_03/leis/leis_2001/l10216.htm>. Acesso em: 07 jan. 2017.

. Lei no 10.406, de 10 de Janeiro de 2002. Código Civil de 2002. Diário Oficial da União. Brasília, DF: Senado, 2002. Disponível em:

<http://www.planalto.gov.br/ccivil_03/leis/2002/L10406.htm>. Acesso em: 10 fev. 2017.

. Lei no 11.343, de 23 de agosto de 2006. Lei de Drogas. Diário Oficial da União. Brasília, DF: Senado, 2006. Disponível em:

<http://www.planalto.gov.br/ccivil_03/_ato2004-2006/2006/lei/111343.htm>. Acesso em: 28 fev. 2017.

. Lei no 13.105, de 16 de Março de 2016. Código de Processo Civil de 2016. Diário Oficial da União. Brasília, DF: Senado, 2016. Disponível em:

<http://www.planalto.gov.br/ccivil_03/leis/2002/L10406.htm>. Acesso em: 09 jan. 2017.

. Ministério da Justiça. Integração de competências no desempenho da atividade judiciária com usuários e dependentes de droga. $2^{a}$ edição. Coord. Arthur Andrade Guerra. Secretaria Nacional de Políticas Sobre Drogas, 2015.

. Ministério da Saúde. Guia Estratégico para Cuidado de Pessoas com Necessidades Relacionadas ao Consumo de Álcool e Outras Drogas - Guia AD. Brasília, DF. 2015

. Superior Tribunal de Justiça; Habeas Corpus n¹35271 / SP, Relator: Min. Sidnei Beneti, Data de Publicação: DJe 04/02/2014, disponível em <https://ww2.stj.jus.br/processo/pesquisa/?src=1.1.3\&aplicacao=processos.ea\&tipoPes quisa=tipoPesquisaGenerica\&num_registro=200900820352>. Acesso em: $18 \mathrm{mar}$. 2017.

. Tribunal de Justiça de Minas Gerais (TJMG). Agravo de Instrumento: Al 10145120720969001 MG, Relator Des. Edilson Fernandes, disponível em: <http://www4.tjmg.jus.br/juridico/sf/proc_complemento2.jsp?listaProcessos=101451207 20969001>. Acesso: 20 fev. 2017.

. Tribunal de Justiça de São Paulo (TJSP). Apelação: APL 00027875620138260160. Relator Des. Carlos Violante, julgado em 16.12.2014, disponível em: <https://esaj.tjsp.jus.br/cjsg/getArquivo.do?cdAcordao $=8108845 \& \mathrm{cdForo}=0 \& \mathrm{vICaptcha}=$ phqju>. Acesso: 20 fev. 2017. 
. Tribunal de Justiça do Maranhão (TJMA). Agravo de Instrumento: Al 0079682012, Relator Desembargador Marcelo Carvalho Silva, julgamento em 07.06.2012, disponível em: < https://jurisprudencia.s3.amazonaws.com/TJ$\mathrm{MA} /$ attachments/TJMA_AI_0079682012_08b2b.pdf?Signature=\%2F7KnxXxr1mLOtndUmFam9Az5oJw\%3 D\&Expires $=1488337 \overline{7} 97 \&$ AWSAccessKeyld=AKIAIPM2XEMZACAXCMBA\&responsecontent-type=application/pdf\&x-amz-meta-md5hash=dca0a3b7aafc371f4c041d05b7009ad0>. Acesso: 20 fev. 2017.

. Tribunal de Justiça do Rio Grande do Sul (TJRS). Apelação e Reexame Necessário - REEX 70046402897 RS, Relator Luiz Felipe Brasil Santos, julgamento em 26.01.2012, disponível em <http://www1.tjrs.jus.br/site_php/consulta/consulta_acordaos.php?Numero_Processo=7 $0046402897 \&$ code $=8710 \&$ entrancia $=2 \& i d$ comarca $=700 \&$ nomecomarca $=\overline{T r i b u n a l} \% 20 \mathrm{~d}$ e\%20Justi\%E7a\&orgao=TRIBUNAL\%20DE\%20JUSTI\%C7A\%20\%208.\%20CAMARA\%20CIVEL>. Acesso: 20 fev. 2017.

- Tribunal de Justiça do Estado do Tocantins (TJTO). Agravo de Instrumento. 0001004-60.2014.827.0000: Relator Desembargados Helvécio Brito de Maia Neto, julgamento em 04/02/2014, disponível em <http://jurisprudencia.tjto.jus.br/documento?uuid=ecbe9726d9aa93448d92f680a5a5283 6\&options=\%23page\%3D1>. Acesso: 18 mar. 2017.

. Tribunal de Justiça do Estado do Tocantins (TJTO). Apelação: APL 00007473520148270000 TO: Relatora Adelina Maria Gurak, julgamento em 16/12/2014, disponível em < http://jurisprudencia.tjto.jus.br/documento?uuid=09f5c935341a8ae303b5014a20e4574d \&options=\%23page\%3D1>. Acesso: 20 fev. 2017.

Tribunal de Justiça do Estado do Tocantins (TJTO). Apelação: APL 00054908820148270000 TO: Relatora Adelina Maria Gurak, julgamento em 15/04/2015, disponível em <http://jurisprudencia.tjto.jus.br/documento?uuid=982b7ba211f9bfb759bb00f9974fa4df\& options=\%23page\%3D1>. Acesso: 20 mar. 2017.

\section{CONEXÃO TOCANTINS. CAPs de Miracema Amplia Atendimentos para}

Transtornos Mentais. Disponível em: <http://conexaoto.com.br/2014/08/25/caps-demiracema-amplia-atendimentos-para-transtornos-mentais>. Acesso em 03 abr. 2017.

. Ministério da Saúde credencia CAPS no Tocantins. Disponível em: <http://conexaoto.com.br/2009/06/09/ministerio-da-saude-credencia-caps-notocantins >. Acesso em: 03 abr. 2017. 
Vertentes do Direito

ISSN n 2359-0106

Vol. 4, n. 2, 2017.

CONSELHO ESTADUAL SOBRE DROGAS DO ESTADO DO TOCANTINS (CONESD). Parecer no 1/CONESD-TO/2016. Palmas/TO, 2016.

CONSELHO FEDERAL DE MEDICINA. Assistência Psiquiátrica. SUS perde mais de 15 mil leitos. Jornal Medicina. Fls.6-7. Fevereiro de 2017.

. Resolução no 1931/2009 do Conselho Federal de Medicina. Diário Oficial da União. Brasília, DF: Senado, 2009. Disponível em:

<http://www.planalto.gov.br/ccivil_03/leis/2002/L10406.htm>. Acesso em: 07 out. 2017.

CONSELHO REGIONAL DE MEDICINA DO TOCANTINS (CRM-TO). 2 Relatório de Vistoria 53/2016. Porto Nacional, 2016.

COSTA, Bernardino Cosobeck da. Análise da efetividade das decisões judiciais de medida de segurança na modalidade de internação no estado do Tocantins. Dissertação (Mestrado Acadêmico) - Universidade Federal do Tocantins. Curso de PósGraduação em Prestação Jurisdicional em Direitos Humanos. Palmas, TO, 2015.

Análise da (in)aplicabilidade das políticas públicas de saúde ao dependente químico na comarca de Colinas do Tocantins/TO: resoluções pactuadas pelo magistrado e a rede socioassistencial In: Revista ESMAT. Tocantins, ano 9, oㅜ 12, p. 87 - 100. Jan./ Jun., 2017.

COSTA, Kaio. Polícia Federal fecha clínica de reabilitação em Araguaína. Jornal do Tocantins. 2017. Disponível em:

<http://www.jornaldotocantins.com.br/editorias/estado/pol\%C3\%ADcia-federal-fechacl\%C3\%ADnica-de-reabilita\%C3\%A7\%C3\%A3o-em-aragua\%C3\%ADna-1.1256270>. Acesso em: 11 abr. 2017.

DEFENSORIA PÚBLICA DO ESTADO DO TOCANTINS (DPE-TO). Relatório de Visita de Inspeção. NAC- Núcleo de Ações Coletivas, NUSA - Núcleo de Defesa da Saúde e NDDH - Núcleo de Defesa dos Direitos Humanos, da DPE-TO. Porto Nacional, 2015.

Nacional, 2013.

Relatório de Visita. NAC - Núcleo de Ações Coletivas da DPE-TO. Porto

DUARTE, Marco José de Oliveira. Da lógica manicomial à rede de atenção psicossocial: a questão das drogas no campo da saúde mental e as internações forçadas. In: FERNANDEZ; Osvaldo Francisco Ribas Lobos; ANDRADE, Marcelo Magalhães. FILHO, Antonio Nery. (Org.). Drogas e políticas públicas: educação, saúde coletica e direitos humanos. Salvador: EDUFBA; Brasília: ABRAMD, 2015. 
ESTADO DO TOCANTINS. Decreto $n^{\circ} 4.604$, de 02 de agosto de 2012. Dispõe sobre o Sistema Estadual de Políticas sobre Drogas, e adota outras providências. Diário Oficial do Estado do Tocantins. Edição no 3.696, fls. 04-06. Brasil, Tocantins. 2012.

Governo do Estado oferta vagas em Comunidades Terapêuticas para a recuperação de dependentes químicos. 07 de dezembro de 2016. Disponível em $<$ http://cidadaniaejustica.to.gov.br/noticia/2016/12/7/governo-do-estado-oferta-vagasem-comunidades-terapeuticas-para-a-recuperacao-de-dependentes-quimicos/>. Acesso em 10 abr. 2017.

. Núcleo Acolher divulga pesquisa sobre perfil de pessoas com dependência química no Tocantins. 04 de maio de 2017. Disponível em: $<$ http://cidadaniaejustica.to.gov.br/noticia/2017/5/4/nucleo-acolher-divulga-pesquisasobre-perfil-de-pessoas-com-dependencia-quimica-no-tocantins/>. Acesso em: 20 mai. 2017.

FIORE, Maurício. O lugar do Estado na questão das drogas: o paradigma proibicionista e as alternativas. Revista Novos Estudos. Ed. oㅜ 92, 2012.

. Uso de "drogas": controvérsias médicas e debate público. Campinas: Mercado de Letras/Fapesp, 2006.

FUNDAÇÃO PERSEU ABRAMO. Em nome da diversidade. 2010. Disponível em < https://fpabramo.org.br/2010/08/04/em-nome-da-diversidade/ >. Acesso em: 14 maio 2017.

GOFFMAN, Erving. Estigma: notas sobre a manipulação da identidade deteriorada. 4. ed. Rio de Janeiro : LTC, 2008.

. Manicômios, prisões e conventos. São Paulo: Editora Perspectiva. 1974.

HAMOY, Ana Celina Bentes. Direitos humanos e medidas socioeducativas: uma abordagem jurídico-social. Belém: Movimento República de Emaús; Centro de Defesa da Criança e do Adolescente (CEDECA-EMAÚS), 2007.

LIMA, Tom. Governo cria Superintendência de Ações sobre Drogas, vinculada à Seciju. Governo do Estado do Tocantins. Cidadania e Justiça. Disponível em $<$ http://cidadaniaejustica.to.gov.br/noticia/2017/4/4/governo-cria-superintendencia-deacoes-sobre-drogas-vinculada-a-seciju/\#sthash.Lbx3KkpJ.dpuf>. Acesso em: 11 abr. 2017.

MACRAE, Edward. Aspectos socioculturais do uso de drogas e políticas de redução de danos. Núcleo de Estudos Interdisciplinares sobre Psicoativos. 2003. 
Vertentes do Direito

ISSN n 2359-0106

Vol. 4, n. 2, 2017.

Disponível em <http://neip.info/novo/wp-content/uploads/2015/04/edward2.pdf>. Acesso em: 20 jan. 2017.

MINISTÉRIO PÚBLICO DO ESTADO DO TOCANTINS (MPE-TO). Inquérito Civil Público no 18/2016. 7 ${ }^{\text {a }}$ Promotoria de Justiça da Comarca de Porto Nacional. Porto Nacional, 2016.

MINISTÉRIO PÚBLICO FEDERAL (MPF). Parecer sobre medidas de segurança e hospitais de custódia e tratamento psiquiátrico sob a perspectiva da Lei $\mathbf{n}$. 10.216/2001. Procuradoria Federal dos Direitos do Cidadão. Brasília, DF. 2011.

OLMO, Rosa del. A face oculta da droga. Tradução: Teresa Ottoni. Rio de Janeiro: Revan, 1990.

ORGANIZAÇÃO MUNDIAL DE SAÚDE (OMS). Classificação Estatística Internacional de Doenças e Problemas Relacionados à Saúde - CID-10. Disponível em: <http://www.datasus.gov.br/cid10/V2008/cid10.htm>. Acesso em: 19 jan. 2017.

. Principles of Drug Dependence Treatment. Discussion paper, march/2008, disponível em <https://www.unodc.org/documents/drug-treatment/UNODC-WHOPrinciples-of-Drug-Dependence-Treatment-March08.pdf >. Acesso em: 20 ago. 2016.

REHFELDT, Luiz Felipe Valente da Silva. A (in) constitucionalidade da internação compulsória dos usuários de crack. Sua aplicação e (in) eficácia. Rio de Janeiro, RJ. 2013. Disponível em <http://www.emerj.tjrj.jus.br/paginas/trabalhos_conclusao/2semestre2013/trabalhos_22 013/LuizFelipeValentedaSilvaRehfeldt.pdf>. Acesso em: 10 fev. 2017. São Paulo: Saraiva, 2016.

SILVA, Manoel Rozeng da. Um estudo sobre a drogadição e os modelos de tratamento. 95f. Monografia (Bacharelado em Direito). UNESC - Universidade do Extremo Sul Catarinense. Criciúma/SC, 2009.

WORM, Naíma. A complexidade das políticas públicas sobre drogas e a polêmica acerca da internção não voluntária. In: ALMEIDA, Cristiane Roque; CARIAGA, Maria Helena; JOVELI, Silvia Regina da Silva Costa. O CRR no Tocantins: articulando saberes para o cuidado em uso abusivo de álcool e outras drogas. Curitiba: CRV, 2017. 